\title{
Characterization of Phomopsis spp. Infecting Grapevines in the Great Lakes Region of North America
}

A. M. C. Schilder, Department of Plant Pathology, Michigan State University, East Lansing 48824; O. Erincik, Department of Plant Pathology, Ohio State University, Wooster 44691; L. Castlebury and A. Rossman, Systemic Botany and Mycology, USDA-ARS, Beltsville, MD 20705; and M. A. Ellis, Department of Plant Pathology, Ohio State University, Wooster 44691

\begin{abstract}
Schilder, A. M. C., Erincik, O., Castlebury, L., Rossman, A., and Ellis, M. A. 2005. Characterization of Phomopsis spp. infecting grapevines in the Great Lakes region of North America. Plant Dis. 89:755-762.

Seventy-five isolates of Phomopsis were obtained from grapes (Vitis spp.) with Phomopsis cane and leaf spot symptoms in Ohio, Michigan, New York, Pennsylvania, Maryland, and Ontario (Canada). Four isolates from California and one from Europe were also included in the study. Isolates were grouped on the basis of DNA sequences from intron regions in the translation elongation factor 1- $\alpha$ and calmodulin genes. According to DNA sequence comparisons with the type isolate, all isolates except two (OH-48 and CAL-5) were determined to be $P$. viticola, confirming the etiology of this disease in the Great Lakes region. Thirty representative isolates were evaluated for mycelial growth rate in vitro, conidial size, and pathogenicity on grapevine (Vitis interspecific hybrid 'Seyval') leaves and internodes. A subsample of 13 isolates was also evaluated for pathogenicity on fruit and rachises. All isolates of $P$. viticola caused disease on grape but differed in virulence. Among $P$. viticola isolates, virulence on leaves and internodes was positively correlated, and virulence on fruit and rachises was positively correlated, but there was no relationship between ratings on vegetative versus reproductive grape tissues. Some isolates that were not virulent on leaves or internodes were highly virulent on fruit and rachises and vice versa, indicating some specialization with respect to host tissues. However, differences were mostly of a quantitative nature, which makes it difficult if not impossible to assign biotypes. Among $P$. viticola isolates, virulence on fruit and rachises was positively correlated with mycelial growth rate in vitro. For the two isolates that were not $P$. viticola, the internal transcribed spacer regions of the nuclear ribosomal DNA were sequenced for identification purposes. Based on the best match available in GenBank, CAL-5 was determined to be close to Diaporthe phaseolorum, while the sequence of OH-48 matched that of Phomopsis sp. from Eucommia ulmoides in China. Both isolates had shorter alpha conidia and significantly higher mycelial growth rates than the P. viticola isolates, and were not or only slightly pathogenic to Vitis interspecific hybrid 'Seyval'.
\end{abstract}

Phomopsis viticola (Sacc.) Sacc. is the causal agent of Phomopsis cane and leaf spot of grapes (Vitis spp.) (14). The fungus can infect all green parts of the grapevine and overwinters in the bark of older canes. Dark brown lesions on the shoots and leaves are the most common symptom of the disease. Cluster symptoms are usually first noticed as the fruit begin to ripen: rachises become necrotic and berries rot or fall to the ground (14). However, worldwide, a number of species of Phomopsis have been isolated from grapevines. In a study conducted by Merrin et al. (11) on Phomopsis from grapevines in Australia,

Corresponding author: A. M. C. Schilder

E-mail: schilder@msu.edu

GenBank accession numbers of DNA sequences: AY745025 to AY745087.

Accepted for publication 14 March 2005.

DOI: 10.1094/PD-89-0755

(C) 2005 The American Phytopathological Society four putative species of Phomopsis, designated Taxon 1, Taxon 2, Taxon 3, and Taxon 4, were found based on the morphology of alpha conidia, appearance of pycnidia, cirrhus color, rate of mycelial growth, and sporulation in vitro. A subsequent study by Phillips (15) suggested that Taxon 1 was Diaporthe perjuncta Niessl and that Taxon 2 represented Phomopsis viticola (Sacc.) Sacc.; the other two taxa were not identified. In 2000, Scheper et al. (20) described the teleomorph of Phomopsis Taxon 1 and considered it to be $D i$ aporthe viticola Nitschke. D. perjuncta was subsequently shown to be nonpathogenic to grapes and is considered an endophyte in grapevines (18).

In a study of Phomopsis spp. associated with grapevines in the Western Cape province of South Africa, six species of Phomopsis, one producing a sexual state and identified as $D$. perjuncta, were characterized, and a neotype specimen and culture were designated ( $P$. viticola STE-U 2660) (12). This study identified Taxon 3 from Merrin et al. (11) as Phomopsis sp. 1, po- tentially a species complex based on ITS sequence data, and Taxon 4 as a species of Libertella. In addition, an isolate from Italian Vitis vinifera was identified as Phomopsis sp. 2, and Phomopsis amygdali was isolated from a South African $V$. vinifera (12). Phomopsis vitimegaspora Kuo \& Leu, the causal agent of swelling arm disease of grapevine in Taiwan (8), was also included in the South African study (12) but found to be unrelated to any of the other isolates.

Subsequently, the European isolates identified as $D$. perjuncta by Phillips (15) and $D$. viticola by Scheper et al. (20) were determined to be $D$. viticola, while the South African and Australian isolates of this taxon have been described as a new species, Diaporthe australafricana Crous \& Niekerk (13). In the latter study, six clades of Phomopsis, consisting of 15 species with at least 8 unidentified species or species complexes, were found, including those in the above-mentioned studies $(11,12)$. In addition, Phomopsis longiparaphysata Uecker \& Kuo (22) has been described from Vitis, although it has not been included in any comparative molecular or cultural studies with other isolates from Vitis. Altogether, 15 species of Phomopsis or Diaporthe have been found in association with grapes. Seven have been identified (P. viticola, $D$. viticola, D. australafricana, $P$. amygdali, $P$. longiparaphysata, $P$. vitamegaspora, $D$. helianthi, and $D$. ambigua), while the others remain unidentified or undescribed.

During 1998 and 1999, severe rachis and berry infections were observed in a 'Vignoles' (Vitis interspecific hybrid) vineyard in southwestern Michigan. Unlike typical Phomopsis infections, few cane and leaf lesions were present in the vineyard. However, P. viticola was consistently isolated from diseased fruit (A. M. C. Schilder, unpublished). Over the past 5 years, rachis infections have been common in juice grape (Vitis labrusca L.) vineyards in Michigan and Ohio, resulting in premature berry drop and moderate to severe crop losses. In most cases, these infections occurred despite regular fungicide spray schedules with protectant fungicides. In 1997, yield losses from Phomopsis cluster infections were estimated at $30 \%$ in several commercial vineyards in southern Ohio. Often these losses were accompa- 
nied by very little cane or leaf infection (M. A. Ellis, unpublished). The variation in symptom development observed in Michigan and Ohio and reports of various Phomopsis species occurring on grapevines in other parts of the world suggested the possibility of a complex of strains or perhaps even different species.

The overall objective of this study was to increase our understanding of the variability of Phomopsis isolates causing disease symptoms on grapes in the Great Lakes region of North America. The specific objectives were to identify and characterize isolates of Phomopsis from grapes, assess their pathogenicity on vegetative and reproductive grape tissues, and determine if pathogenicity or morphological characteristics are correlated with DNA sequence variation.

\section{MATERIALS AND METHODS}

Isolate origin and maintenance. Eighty Phomopsis isolates were obtained from grapevines (Vitis vinifera L., Vitis labrusca L., and Vitis interspecific hybrids) showing typical symptoms of Phomopsis cane and leaf spot disease. The following locations, with numbers of isolates, were represented in the study: Ohio $(\mathrm{OH}): 40$; Michigan (MI): 10; New York (NY): 7; Pennsylvania (PA): 4; Maryland (MD): 1; Ontario (ON), Canada: 13; California (CAL): 4; and France (EUR): 1. Isolates were stored in liquid nitrogen at the Ohio Agricultural Research and Development Center, Wooster.

Nucleic acid extraction and polymerase chain reaction (PCR) amplification. The Phomopsis isolates listed above were used for this study, as was the neotype culture of $P$. viticola STE-U 2660 (12). Mycelia for DNA extraction were grown for 5 to 10 days at room temperature under ambient light conditions in shaker flasks (125 rpm) containing $100 \mathrm{ml}$ of liquid complete yeast medium (CYM) (17). Mycelia were harvested by vacuum filtration on Whatman No. 1 filter paper and freeze-dried prior to DNA extraction. Genomic DNA was extracted with the DNeasy Plant Mini kit (Qiagen Inc., Chatsworth, CA) according to the manufacturer's instructions using approximately $15 \mathrm{mg}$ of dried tissue. Alternatively, DNA was extracted from approximately $50 \mathrm{mg}$ of mycelium scraped from the surface of a 3- to 5-day-old culture growing on Difco potato dextrose agar (PDA).

Two gene fragments were amplified from extracted DNA. Primers EF1-728F (5'-CATCGAGAAGTTCGAGAAGG) and EF1-986R (5'-TACTTGAAGGAACCCTTACC) were utilized for an intron region of the translation elongation factor 1-alpha (EF1- $\alpha$ ) gene (2). Another intron region in the calmodulin gene was amplified using primers CAL-228F (5'-GAGTTCAAGGAGGCCTTCTCCC) and CAL-737R (5'CATCTTTCTGGCCATCATGG) (1). For the two non- $P$. viticola isolates $(\mathrm{OH}-48$, CAL-5), the internal transcribed spacer (ITS) regions 1 and 2 including the 5.8S rDNA were amplified using primers ITS 5 $\left(5^{\prime}-\right)$ and ITS 4 (5'-TCCTCCGCTTATTGATATGC) (25).

Gene fragments were amplified in 50- $\mu \mathrm{l}$ reactions on a GeneAmp 9700 thermal cycler (Applied Biosystems, Foster City, CA) under the following reaction conditions: 10 to $15 \mathrm{ng}$ of genomic DNA, 200 mM each dNTP, 2.5 units Amplitaq Gold (Applied Biosystems), 25 pmoles of each primer, and $10 \mu \mathrm{l}$ of the supplied $10 \times \mathrm{PCR}$ buffer with $15 \mathrm{mM} \mathrm{MgCl}_{2}$. The thermal cycler program was as follows: $10 \mathrm{~min}$ at $95^{\circ} \mathrm{C}$ followed by 35 cycles of $30 \mathrm{~s}$ at $94^{\circ} \mathrm{C}, 30 \mathrm{~s}$ at $55^{\circ} \mathrm{C}$, and $1 \mathrm{~min}$ at $72^{\circ} \mathrm{C}$, with a final extension period of $10 \mathrm{~min}$ at $72^{\circ} \mathrm{C}$. After amplification, the PCR products were purified with QIAquick columns (Qiagen) according to the manufacturer's instructions. Amplified products were sequenced with the BigDye version 2.0 ready reaction kit (Applied Biosystems) on an ABI 310 automated DNA sequencer.

Sequence analysis. Raw sequences were edited using Sequencher version 4.05 for Windows (Gene Codes Corporation, Ann Arbor, MI) and are deposited in GenBank as accession numbers AY745025 to AY745087. Alignments were adjusted manually using GeneDoc 2.6.001 (distributed by K. Nicholas). Trees were inferred using PAUP* 4.0b10 (Sinauer, Sunderland, $\mathrm{MA})$ with the following methods: the neighbor joining $(\mathrm{NJ})$ method (Kimura 2parameter distance calculation) and maximum parsimony (MP) using the heuristic search (random addition with 1,000 replicates) with TBR-branch swapping and the MULTREES option turned on. For MP analyses, heuristic searches resulted in more than 10,000 trees before terminating the search. Because of the large number of equally parsimonious trees generated in each replicate, a maximum of 20 trees per replicate was saved per random sequence addition replicate with unlimited MAXTREES. All molecular characters were unordered and given equal weight during analysis. For parsimony analysis, parsimony informative characters were analyzed and gaps were treated as missing data. For neighbor joining analyses, gaps were ignored. Relative support for the branches was estimated with 1,000 bootstrap replications (6) for NJ and MP analyses. Additionally, for MP bootstrap analyses, 10 random sequence additions per bootstrap replicate were performed with TBR branch swapping on and the MULTREES option turned off. The partition homogeneity test (PHT) as implemented in PAUP* $4.0 \mathrm{~b} 10$ was used to test the congruence between the EF1- $\alpha$ and calmodulin data sets (3). For this test, constant characters were excluded, gaps were treated as missing data, and 500 repetitions were run.
Cultural and morphological studies. To study the relative growth rates of Phomopsis isolates from grapevine, 30 representative isolates were selected from the 80 isolates that were used in the sequence analysis: two isolates from group I (CAL5, OH-48), 14 isolates from group II (CAL-1, CAL-2, CAN-3, CAN-9, EUR-2, MD-1, MI-5, MI-8, OH-2, OH-9, OH-12, $\mathrm{OH}-25, \mathrm{OH}-45, \mathrm{OH}-61$ ), and 14 isolates from group III (CAN-12, MI-1, MI-2, MI10, NY-2, NY-6, NY-7, OH-1, OH-7, OH19, OH-22, OH-30, OH-36, OH-54). The isolates were transferred to PDA from plates stored at $4^{\circ} \mathrm{C}$, and incubated at 22 to $23^{\circ} \mathrm{C}$. Mycelial plugs $(7 \mathrm{~mm}$ diameter $)$ from the growing edge of these cultures were then transferred to the middle of 9$\mathrm{cm}$ petri plates with PDA (three plates per isolate). The plates were placed in the dark in incubators set at 5, 10, 15, 20, 25, and $30^{\circ} \mathrm{C}$. Colony diameter was measured in two perpendicular directions on each plate after 7 and 14 days of incubation. The experiment was conducted twice. In the first experiment, isolates MD-1 and OH-61 were not included. In the second experiment, the $5^{\circ} \mathrm{C}$ treatment was eliminated, as little or no growth had been observed previously at that temperature.

For conidial measurements, fresh mycelial plugs of these same isolates were placed on pieces of autoclaved grape leaves on water agar in $9-\mathrm{cm}$ petri dishes to stimulate pycnidium formation. There were three replicate plates per isolate. After 1 to 2 weeks of incubation at $25^{\circ} \mathrm{C}$ in $12 \mathrm{~h}$ per day of fluorescent light, conidia oozing out of pycnidia were picked up with sterile toothpicks and placed in a drop of sterile water on microscope slides. The length and width of 15 randomly selected alpha conidia per isolate (five per replicate) were measured using a calibrated ocular micrometer at $\times 400$ magnification. Beta conidia were measured when present.

Plant production and maintenance. For leaf and internode inoculations, symptomless stem cuttings were collected from field-grown 'Seyval' (Vitis interspecific hybrid) plants during the pruning season in 2001. Dormant cuttings were placed in a misted cutting bed and allowed to grow roots. Rooted cuttings were planted in a mixture of peat, steam-disinfested loam, and perlite $(1: 1: 1, \mathrm{vol} / \mathrm{vol} / \mathrm{vol})$ in $15-\mathrm{cm}$ diameter pots. Each plant was trained to a single shoot and allowed to grow in the greenhouse until it had at least six leaves. Plants were fertilized with $13 \mathrm{~g}$ of Osmocote 14-14-14 (Scotts Company, Marysville, $\mathrm{OH}$ ) every 2 months, and watered as needed with deionized water. The four youngest leaves and internodes per shoot were tagged for inoculation.

For cluster inoculations, potted plants of 'Seyval' with intact clusters were produced. Bare-rooted cuttings were planted in a mixture of peat, steam-disinfested loam, and perlite in 20 -cm-diameter plastic 
pots in May. Plants were trained to a single shoot and allowed to grow outside until they became dormant in November. Dormant plants were placed in cold storage $\left(0^{\circ} \mathrm{C}\right)$ until March, when they were placed in the greenhouse. Shortly after budbreak, vines were cut to a height of approximately $50 \mathrm{~cm}$. Two buds with fruit clusters were selected and each plant was trained to two shoots with one cluster per shoot. Plants were fertilized with $18 \mathrm{~g}$ of Osmocote every other month and were watered as needed with deionized water, taking care not to wet flower or fruit clusters.

Inoculation of leaves and internodes. Inoculations were conducted with the same 30 Phomopsis isolates used in the culturalmorphological study. Cultures were grown on PDA in petri plates at $21^{\circ} \mathrm{C}$ under continuous fluorescent light at $58 \mu \mathrm{E} \cdot \mathrm{m}^{-2} \cdot \mathrm{s}^{-1}$ for 15 to 20 days. Conidia were collected by flooding culture plates with sterile deionized water. Pycnidia and conidia were dislodged by rubbing the surface with a paint brush. The suspension was filtered through four layers of cheesecloth and adjusted to $1 \times 10^{7}$ alpha conidia per milliliter using a hemacytometer.

A conidial suspension from each isolate was sprayed until runoff onto previously tagged leaves and internodes of five plants per replication (two replications per isolate) by using an atomizer. Noninoculated control plants were sprayed with water only. Inoculated and control plants were placed in a moist chamber maintained at

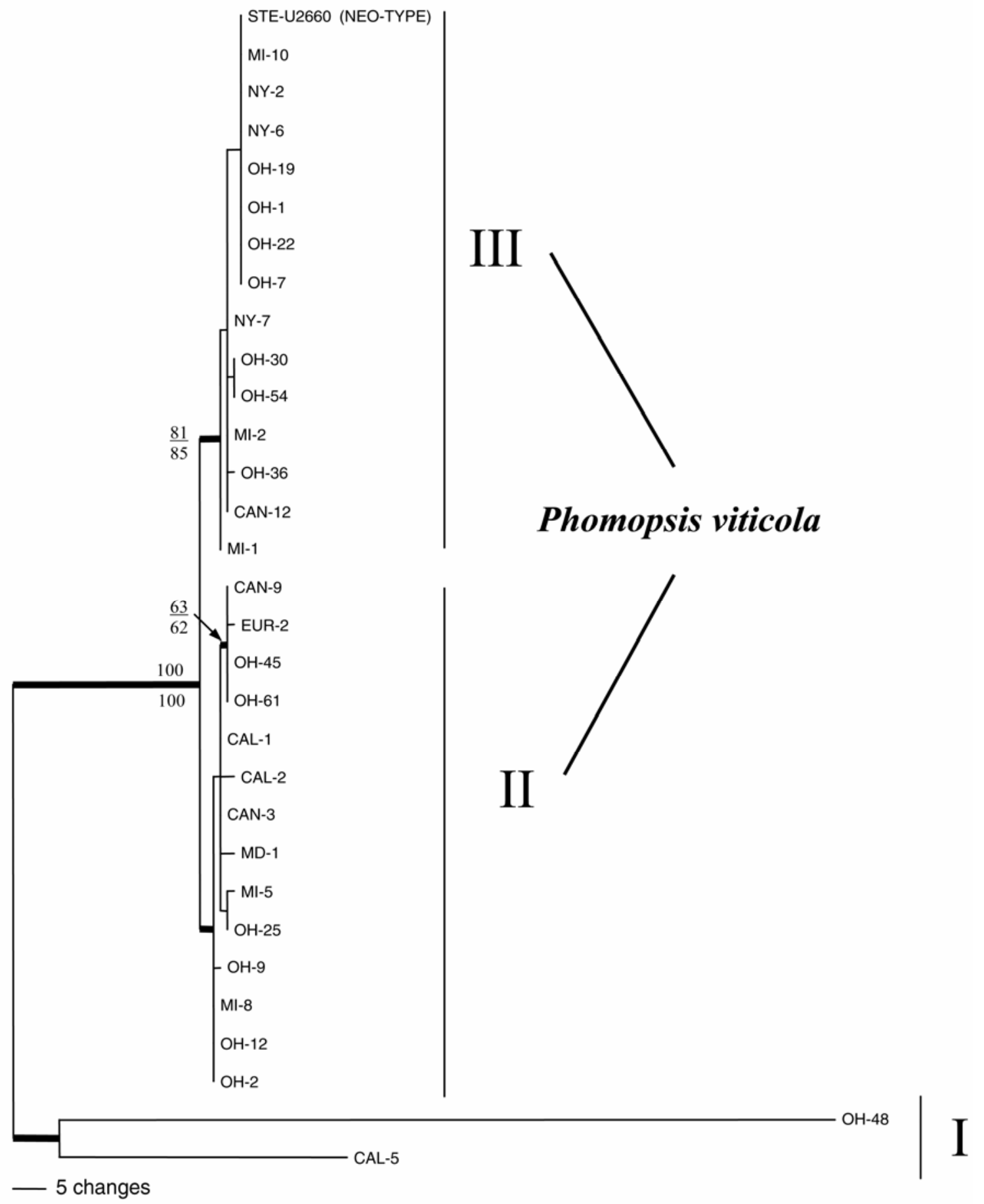

Fig. 1. One of 3,178 equally parsimonious trees generated by sequence analysis of the translation elongation factor 1- $\alpha$ and calmodulin genes in Phomopsis spp. isolated from grapevines. Thickened lines indicate branches present in the strict consensus tree. Support for branches represents percentage of 1,000 bootstrap replicates containing that branch. maximum parsimony (MP) bootstrap percentages $>50 \%$ are above the branch with neighbor joining (NJ) bootstraps below. The two isolates representing group I were not identified as $P$. viticola. 
$20^{\circ} \mathrm{C}$ and continuous light for $24 \mathrm{~h}$. After a 24-h wetting period, plants were moved to a greenhouse and watered on the soil surface to avoid wetting the leaves and internodes. Disease severity on leaves was assessed by estimating the number of lesions on each of four leaves per plant 15 days after inoculation. The following rating scale was used: $0=$ no lesions, $1=1$ to 10 lesions, $2=11$ to 25 lesions, $3=26$ to 50 lesions, $4=51$ to 75 lesions, $5=76$ to 100 lesions, and $6=>100$ lesions per leaf (5). Disease severity on the internodes was assessed by estimating the proportion of the area covered by lesions on four tagged internodes per plant using the HorsfallBarratt scale (7) 30 days after inoculation. The experiment was set up in a randomized complete block design and was conducted three times.

Inoculation of fruit clusters. A subset of 13 of the 30 Phomopsis isolates was used for inoculation of fruit clusters: two isolates from group I (CAL-5, OH-48), five isolates from group II (CAL-2, CAN9, EUR-2, MI-8, OH-12), and six isolates from group III (CAN-12, MI-10, NY-2, NY-7, OH-19, OH-22). Inoculum for each isolate was prepared and applied as previously described to clusters at EichhornLorenz growth stage 33 (beginning of berry touch) $(4,5)$. One cluster per plant was inoculated on five plants per replication (two replications per isolate). Clusters on control plants were sprayed with water only. Plants were then placed in a moist chamber at $20^{\circ} \mathrm{C}$ for $24 \mathrm{~h}$ and returned to the greenhouse after a 24-h wet period. Plants were observed daily, and the presence of symptoms on fruits and rachises was recorded. Individual berries were harvested weekly as Phomopsis fruit rot symptoms developed near maturity. The experiment was terminated, and all clusters were harvested when berries reached an average of $21 \%$ soluble solids, as meas-

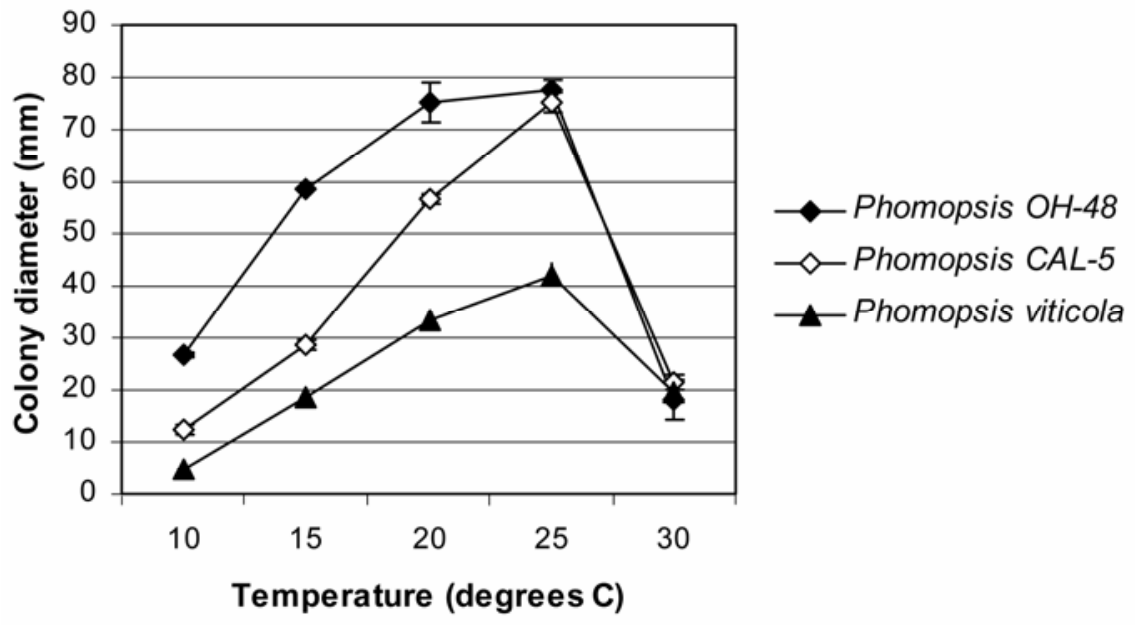

Fig. 2. Average colony diameter of Phomopsis isolates from grapevine on potato dextrose agar after 7 days of dark incubation at a range of temperatures (exp. 2). P. viticola values represent the means of 28 isolates with three replicates per isolate, whereas values for single isolates Phomopsis $\mathrm{OH}-48$ and CAL-5 are means of three replicates per isolate. Error bars indicate the standard error of the mean.
P. viticola isolates (OH-48 and CAL-5) were not included in the regressions.

\section{RESULTS}

Sequence analysis. The EF1- $\alpha$ gene for all 80 strains of Phomopsis was sequenced. All but two were identified as $P$. viticola based on a comparison with the neotype isolate (STE-U2660) as designated by Mostert et al. (12). A BLAST search of GenBank was performed for the ITS sequences of the two non- $P$. viticola isolates, CAL-5 and OH-48. For the CAL-5 ITS sequence, the best match was Diaporthe phaseolorum strain 793-a (AF001014) from soybean with identities $=503 / 518$ $(97 \%)$ and gaps $=2 / 518(<1 \%)$. In addition, CAL-5 shared 454/466 identities with Phomopsis Taxon 3/species 1 strain STEU2661, suggesting a relationship with this complex previously recovered from Vitis in Australia $(11,12)$. For $\mathrm{OH}-48$, the best match available in GenBank was a Phomopsis sp. isolate from Eucommia ulmoides Oliv. in China.

The EF1- $\alpha$ gene region consisted of 345 or $346 \mathrm{bp}$ for the $P$. viticola isolates, whereas for the non- $P$. viticola isolates, it consisted of 368 bp (OH-48) or 356 bp (CAL-5). Eleven positions differed among the $P$. viticola isolates for the EF1- $\alpha$ gene. The EF1- $\alpha$ sequence alignment consisted of 374 total characters, of which 40 were parsimony informative. The calmodulin gene region consisted of 517 bp for all isolates, except $\mathrm{OH}-48$ (515 bp). Six positions differed among the $P$. viticola isolates for the calmodulin gene. The calmodulin alignment consisted of 521 total characters, of which five were parsimony informative. The calmodulin gene was unable to be sequenced for 2 isolates, NY-7 and $\mathrm{OH}-48$.

The partition homogeneity test indicated incongruence between the data partitions $(P=0.006)$. This is thought to be due to the small number of parsimonyinformative characters in the calmodulin gene and the general lack of resolution provided by that gene. However, data sets were combined to provide total evidence for differences among isolates. Analysis of the EF1- $\alpha$ gene alone resulted in the same topology as found by the combined analysis, whereas analysis of the calmodulin gene alone resulted in a topology that differed slightly in the arrangement of the terminal isolates within the $P$. viticola group (trees not shown). A total of 3,178 equally parsimonious trees resulted from the combined analysis of the EF1- $\alpha$ and calmodulin genes. Parsimony tree scores were: CI (consistency index) $=0.902$, RI (retention index $)=0.962, \mathrm{RC}$ (rescaled consistency index $)=0.868$, and length $=$ 51 (6). The $P$. viticola isolates were supported with $100 \%$ bootstrap support in both MP and NJ analyses. Three groups of isolates were present in all MP trees (Fig. 1), while NJ analysis resolved one group 


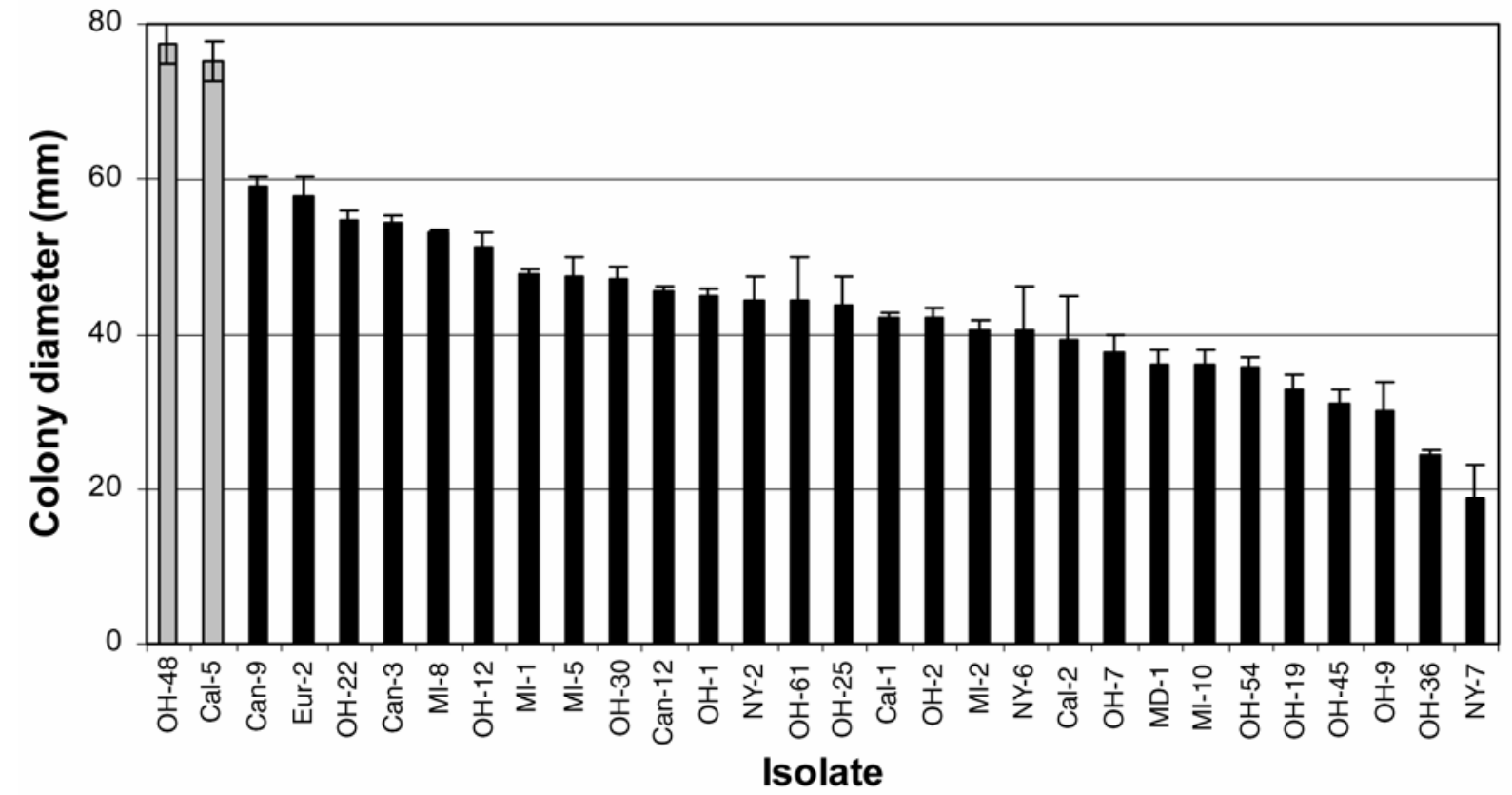

Fig. 3. Colony diameter of Phomopsis isolates from grapevine after 7 days of dark incubation on potato dextrose agar at $25^{\circ} \mathrm{C}$ (exp. 2). Gray bars represent non- $P$. viticola isolates and black bars represent $P$. viticola isolates. Values represent the means of three replicates per isolate. Error bars indicate the standard error of the mean $\left(\mathrm{LSD}_{0.05}=7.3\right)$.

Table 1. Genetic grouping, average size of $\alpha$-conidia, and virulence on 'Seyval' grapes of Phomopsis spp. isolated primarily from grapevines in the Great Lakes region of North America

\begin{tabular}{|c|c|c|c|c|c|c|c|c|c|c|}
\hline \multirow{2}{*}{$\frac{\text { Isolate }}{\text { P. viticola }}$} & \multirow[t]{2}{*}{$\begin{array}{l}\text { Genetic } \\
\text { group }^{v}\end{array}$} & \multirow[t]{2}{*}{$\begin{array}{c}\text { Average size } \\
\alpha \text {-conidia }(\mu \mathrm{m})\end{array}$} & \multicolumn{2}{|c|}{ No. lesions per leaf ${ }^{w}$} & \multicolumn{2}{|c|}{$\begin{array}{c}\% \text { Internode } \\
\text { area diseased }^{\mathrm{w}}\end{array}$} & \multicolumn{2}{|c|}{$\%$ Berries infected $^{\mathrm{x}}$} & \multicolumn{2}{|c|}{$\begin{array}{c}\% \text { Rachis } \\
\text { areas diseased }\end{array}$} \\
\hline & & & & & & & & & & \\
\hline OH-9 & II & $10.0 \times 3.7$ & 83.1 & $a^{y}$ & 15.6 & $a b c$ & -z & - & - & - \\
\hline MI-2 & III & $10.2 \times 4.0$ & 81.5 & $a b$ & 20.6 & $\mathrm{a}$ & - & - & - & - \\
\hline MD-1 & II & $10.7 \times 3.3$ & 80.0 & $a b c$ & 11.3 & bcde & - & - & - & - \\
\hline NY-6 & III & $11.6 \times 4.4$ & 79.6 & $a b c$ & 13.4 & abcde & - & - & - & - \\
\hline NY-7 & III & $10.7 \times 4.1$ & 77.3 & abcd & 9.4 & cde & 23.1 & ef & 6.4 & de \\
\hline $\mathrm{OH}-2$ & II & $11.0 \times 4.5$ & 76.5 & abcd & 12.5 & abcde & - & - & - & - \\
\hline CAL-1 & II & $10.2 \times 4.5$ & 76.0 & abcd & 11.9 & bcde & - & - & - & - \\
\hline MI-10 & III & $10.1 \times 3.8$ & 75.7 & abcd & 11.4 & bcde & 15.7 & fg & 3.0 & ef \\
\hline $\mathrm{OH}-45$ & II & $12.6 \times 4.1$ & 75.5 & abcd & 9.2 & cde & - & - & - & - \\
\hline OH-19 & III & $11.0 \times 4.2$ & 73.5 & abcd & 12.7 & abcde & 34.7 & de & 7.2 & cde \\
\hline $\mathrm{OH}-25$ & II & $9.8 \times 4.0$ & 73.3 & abcd & 12.5 & abcde & - & - & - & - \\
\hline $\mathrm{OH}-22$ & III & $12.1 \times 3.1$ & 67.8 & abcd & 6.9 & cdef & 50.4 & bcd & 19.1 & $\mathrm{bc}$ \\
\hline CAN-9 & II & $10.5 \times 4.1$ & 66.7 & abcd & 13.1 & abcde & 87.4 & $\mathrm{a}$ & 55.5 & $\mathrm{a}$ \\
\hline NY-2 & III & $10.1 \times 4.5$ & 66.1 & abcd & 15.0 & abcd & 40.7 & cde & 15.0 & bcd \\
\hline MI-5 & II & $10.0 \times 3.8$ & 64.0 & abcd & 11.5 & bcde & - & - & - & - \\
\hline MI-8 & II & $10.7 \times 3.9$ & 63.9 & abcd & 18.3 & $\mathrm{ab}$ & 35.4 & de & 18.0 & bcd \\
\hline $\mathrm{OH}-7$ & III & $9.9 \times 4.1$ & 63.0 & abcd & 8.1 & cdef & - & - & - & - \\
\hline $\mathrm{OH}-12$ & II & $11.2 \times 4.5$ & 60.8 & abcd & 9.7 & cde & 58.4 & $\mathrm{bc}$ & 22.8 & $\mathrm{~b}$ \\
\hline MI-1 & III & $9.8 \times 3.7$ & 59.0 & abcd & 5.7 & ef & - & - & - & - \\
\hline OH-54 & III & $10.3 \times 4.3$ & 58.0 & abcd & 7.4 & cdef & - & - & - & - \\
\hline CAN-12 & III & $10.5 \times 3.7$ & 57.9 & abcd & 7.4 & cdef & 60.5 & $\mathrm{~b}$ & 29.6 & $\mathrm{~b}$ \\
\hline $\mathrm{OH}-30$ & III & $10.0 \times 4.0$ & 56.7 & abcd & 7.1 & cdef & - & - & - & - \\
\hline $\mathrm{OH}-1$ & III & $9.9 \times 3.8$ & 52.2 & bdc & 10.2 & bcde & - & - & - & - \\
\hline CAL-2 & II & $9.9 \times 4.0$ & 50.3 & $\mathrm{dc}$ & 7.8 & cdef & 5.0 & gh & 1.7 & ef \\
\hline $\mathrm{OH}-36$ & III & $10.3 \times 3.5$ & 49.4 & $\mathrm{~d}$ & 6.6 & def & - & - & - & - \\
\hline $\mathrm{OH}-61$ & II & $11.0 \times 4.4$ & 10.1 & $\mathrm{e}$ & 0.8 & $\mathrm{f}$ & - & - & - & - \\
\hline CAN-3 & II & $10.6 \times 4.2$ & 5.1 & $\mathrm{e}$ & 0.7 & $\mathrm{f}$ & - & - & - & - \\
\hline EUR-2 & II & $10.5 \times 4.3$ & 0.0 & $\mathrm{e}$ & 0.3 & $\mathrm{f}$ & 67.0 & $\mathrm{~b}$ & 27.7 & $\mathrm{~b}$ \\
\hline \multicolumn{11}{|c|}{ Non- $P$. viticola } \\
\hline OH-48 & I & $7.1 \times 3.5$ & 0.3 & $\mathrm{e}$ & 0.2 & $\mathrm{f}$ & 14.6 & fg & 0.0 & $\mathrm{f}$ \\
\hline CAL-5 & I & $7.9 \times 3.8$ & 0.0 & e & 0.1 & $\mathrm{f}$ & 0.0 & $\mathrm{~h}$ & 0.0 & $\mathrm{f}$ \\
\hline \multicolumn{2}{|c|}{ Water-inoculated control } & - & 0.0 & $\mathrm{e}$ & 0.0 & $\mathrm{f}$ & 0.0 & $\mathrm{~h}$ & 0.0 & $\mathrm{f}$ \\
\hline
\end{tabular}

\section{${ }^{v}$ See Figure 1.}

${ }^{\mathrm{w}}$ Mean of four leaves or internodes per plant on 10 plants (five plants per replication, two replications per isolate).

${ }^{x}$ Mean of 10 clusters (five clusters per replication, two replications per isolate). Actual data are shown but statistical analysis was done on arcsine-squareroot-transformed data.

${ }^{y}$ Means within a column followed by a common letter are significantly different according to Fisher's protected LSD $(P=0.05)$.

${ }^{\text {z }}$ Not tested. 
of all $P$. viticola isolates from the two non$P$. viticola isolates. One arbitrarily chosen midpoint rooted MP tree is shown in Figure 1 with thickened lines indicating branches present in the strict consensus tree. Bootstrap values greater than $50 \%$ are indicated above (MP) and below (NJ) the respective branches.

Cultural and morphological studies. Virtually all $P$. viticola isolates, as well as the two non- $P$. viticola isolates, showed optimum mycelial growth at $25^{\circ} \mathrm{C}$ in both experiments (Fig. 2, only results of experiment 2 shown). The $25^{\circ} \mathrm{C}$ temperature was therefore selected to compare the growth rates of individual isolates. Colony diameter after 7 days of incubation was chosen because the fastest-growing isoby that time. The two non- $P$. viticola isolates (OH-48 and CAL-5) grew significantly faster than all $P$. viticola isolates (Fig. 3, only results from experiment 2 shown). While $P$. viticola isolates expressed a continuous range of growth rates lates had not reached the edge of the plate

at this temperature, $\mathrm{OH}-26$ and NY-7 grew significantly more slowly than the other isolates. There was a significant overall effect of isolate, experiment, and experiment $x$ isolate interaction on growth rate. While most isolates behaved similarly between the two experiments, there were a few isolates that changed ranks, possibly due to sectoring.

The average size of the alpha conidia of the $P$. viticola isolates in this study ranged from 9.8-12.6 $\times 3.1-4.5 \mu \mathrm{m}(\mathrm{Ta}-$ ble 1). Some isolates showed more variability than others. Conidium length was not correlated with genetic grouping, growth rate, or virulence on grapevine tissues. Only five isolates produced beta conidia, which varied in size from 23.0$29.6 \times 1.5-2.9 \mu \mathrm{m}$. The alpha conidia of the non- $P$. viticola isolates, $\mathrm{OH}-48$ and CAL-5, were significantly shorter than those of P. viticola (Table 1). Neither produced beta conidia.

Pathogenicity and virulence on grapevine. Most isolates of $P$. viticola
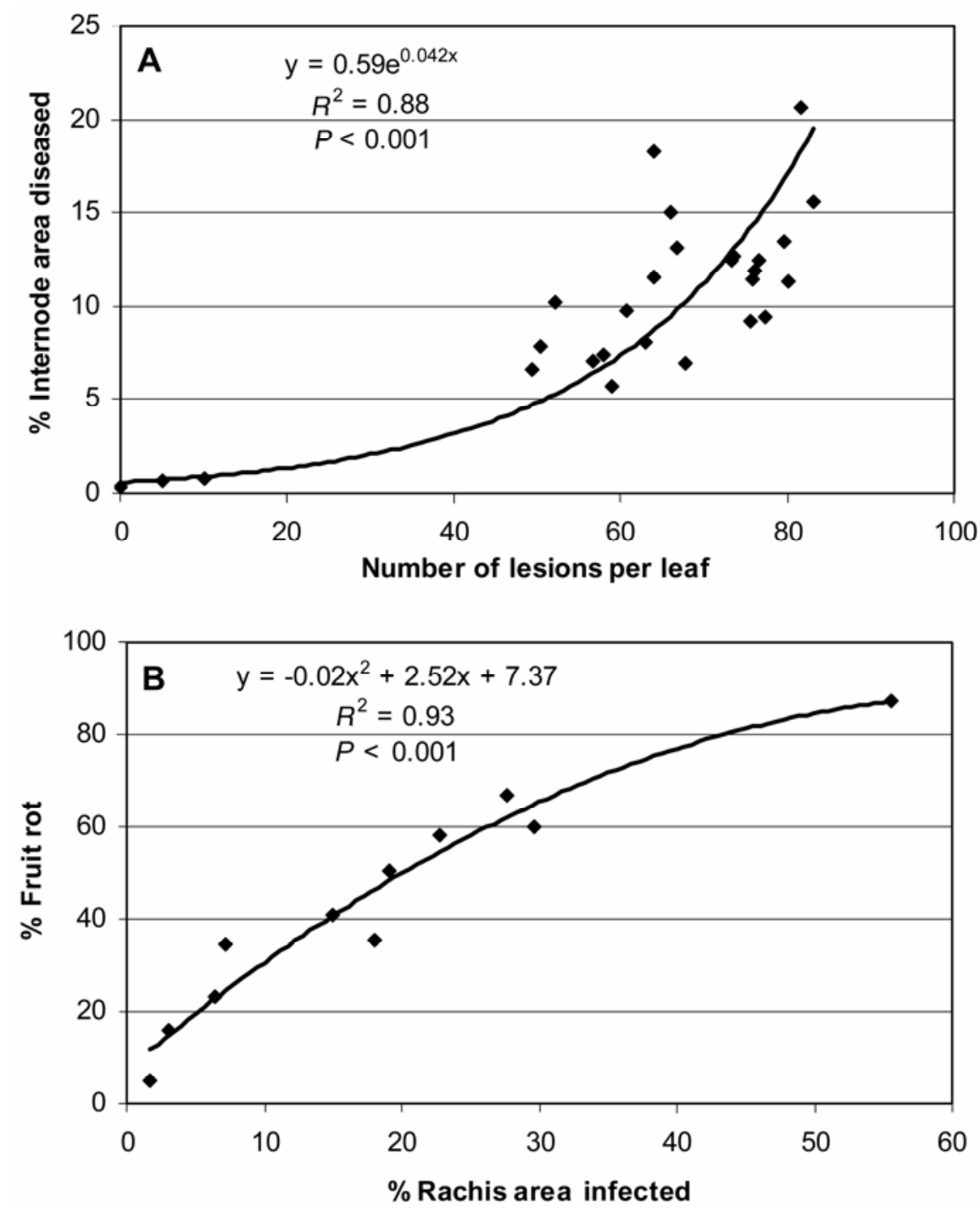

Fig. 4. Relationship between disease severity caused by Phomopsis viticola isolates from grapevine on $\mathbf{A}$, leaves and canes, and $\mathbf{B}$, fruit and rachises of grapevines (Vitis interspecific hybrid 'Seyval'). NonP. viticola isolates (OH-48 and CAL-5) are not included. were pathogenic on leaves and internodes. However, isolates displayed a great deal of variation in the amount of disease produced on these tissues (Table 1). The non$P$. viticola isolates (CAL-5 and OH-48) were not pathogenic, whereas three isolates of $P$. viticola in group II $(\mathrm{OH}-61$, CAN-3, and Eur-2) were only slightly or not pathogenic on leaves and internodes (Table 1).

Of the 13 isolates inoculated onto clusters, 11 caused a significant amount of fruit rot (Table 1). Isolates of $P$. viticola causing fruit rot belonged to groups II or III. The non- $P$. viticola isolate CAL-5 did not produce fruit rot, while $P$. viticola CAL-2 produced only $5 \%$ fruit rot, which was not significantly different from the noninoculated control. The incidence of fruit rot among the other isolates ranged from 14.6 to $87.4 \%$, indicating a high degree of variability between isolates in virulence on berries. The non- $P$. viticola isolate $\mathrm{OH}-48$ produced $14.6 \%$ fruit rot with symptoms identical to those produced by $P$. viticola (Table 1).

Specialization on specific plant tissues was evident in some $P$. viticola isolates. For instance, EUR-2 produced severe disease on fruit and rachises but was not pathogenic on leaves and internodes. Conversely, CAL-2 was fairly virulent on leaves and internodes but caused little disease on berries and rachises. MI-10 also caused severe disease on leaves and internodes and relatively little disease on clusters. Differences in virulence on vegetative and reproductive grape tissues were less pronounced for the remainder of the isolates.

Disease severity caused by $P$. viticola on leaves was positively correlated with that on internodes in an exponential fashion $\left(R^{2}\right.$ $=0.88, P<0.001)$ Results of the second experiment are shown because all isolates were represented (Fig. 4A). Similarly, disease severity on the fruit was positively correlated in a polynomial fashion with that on the rachis $\left(\operatorname{adj} R^{2}=0.93, P<\right.$ 0.001) (Fig. 4B). Regressions of disease severity on the leaves or internodes against virulence on the rachis or fruit were not significant. However, disease severity caused by $P$. viticola isolates on the rachis and fruit was positively correlated in a polynomial fashion with their growth rate in vitro $\left(\operatorname{adj} R^{2}=0.57, P=0.014 ; \operatorname{adj} R^{2}=\right.$ $0.56, P=0.015$, respectively in experiment 2) (Fig. 5). This was not the case with disease severity on vegetative tissues. In fact, there was a weak but significant negative linear correlation between colony growth rate and the number of leaf lesions $\left(R^{2}=0.19, P=0.02\right)$ and no correlation between growth rate and internode disease severity (graphs not shown). Results of regressions against growth rate in experiment 1 were similar, but in general, the $R^{2}$ values were slightly smaller (results not shown). 


\section{DISCUSSION}

In this study, two taxa of Phomopsis were found to be associated with grapes in the North American Great Lakes region. $P$. viticola was isolated from 73 out of 74 grape samples with typical symptoms of Phomopsis cane and leaf spot. Only one isolate $(\mathrm{OH}-48)$ was different, resembling a Phomopsis isolate from Eucommia ulmoides Oliv. (hardy rubber tree) in China. Since this isolate was uncommon and was only able to cause a small amount of fruit rot on grapes, it may have originated from another host in the vicinity of the vineyard and is thought to be of little significance to grape production in the region. Among the four isolates included from California, three were $P$. viticola and one (CAL-5) closely matched Diaporthe phaseolorum, a pathogen of soybean. However, CAL-5 was virtually nonpathogenic to grape and could have been an endophyte, similar to Diaporthe perjuncta in Australia (18). This isolate also showed ITS sequence similarities to Taxon 3/species 1 (11-13) and is potentially a member of this complex. Considering the range of Phomopsis/Diaporthe species found on grapes in other parts of the world $(8,11-13,22)$, variation in this study was rather limited, which simplifies disease diagnosis and control efforts.

Sequence data from the two intron regions of the EF1- $\alpha$ and calmodulin genes suggest that two distinct subgroups of $P$. viticola isolates exist in the Great Lakes region. The genetic grouping was not correlated with geographic origin, growth rate, conidial size, or virulence of the isolates. Considerable variability was observed in mycelial growth rate in vitro, whereas size of the alpha conidia was relatively uniform within $P$. viticola in this study. Average alpha conidial size (9.8$12.6 \times 3.1-4.5 \mu \mathrm{m})$ was fairly consistent with Mostert et al. (12), given as (7-)9.5$10.5(-13) \times(1.5-) 2-3(-3.5) \mu \mathrm{m}$, although slightly larger than that mentioned by Pearson and Goheen $(7-10 \times 2-4 \mu \mathrm{m})(14)$. This may be due to differences in growth media or the wide range of isolates studied. Both a significantly higher growth rate and shorter conidia set apart the two non- $P$. viticola isolates, confirming the sequencing results.

All P. viticola isolates tested were capable of causing disease on certain grapevine tissues. However, they varied widely in the amount of disease they caused, indicating differences in virulence. Since only one cultivar of grape ('Seyval') was used, it was not possible to detect differential virulence to host genotypes, although this would certainly merit further study. Variation in virulence has not been reported previously in $P$. viticola, even though it is known to occur in other Phomopsis species, such as Phomopsis longicolla on soybean (23) and Phomopsis helianthi on sunflower (24). Physiologic races have been identified in Diaporthe phaseolorum var. meridionalis in Brazil based on pathogenicity on a differential set of soybean genotypes (16).

This study is also the first to report variation in tissue specificity among certain isolates of $P$. viticola, e.g., EUR-2, which was highly virulent on reproductive tissues and virtually nonpathogenic on vegetative tissues. Viguié et al. (24) also reported some interactions between isolates of $P$. helianthi and different sunflower tissues. Biochemical factors may play a role, as the properties of cutinase enzymes produced by different fungal species were found to influence tissue specificity (21). However, very little is known about tissue specificity in fungal pathogens in general. In the case of $P$. viticola, specificity of certain isolates for grapevine clusters may help explain field observations, although environmental factors and variability in fungicide coverage cannot be ruled out. Variation in virulence as well as tissue specificity observed among $P$. viticola isolates have potential implications for grape breeding efforts, particularly in the choice of isolates used in screening for resistance and the need to evaluate resistance of both vegetative and reproductive tissues.

A positive correlation was found between virulence of $P$. viticola isolates on clusters and mycelial growth rate in vitro. Positive correlations between mycelial growth rate and virulence have also been reported in Colletotrichum gloeosporioides infecting avocado fruits (19) and Colletotrichum gossypii var. cephalosporioides infecting cotton (9). In contrast, a negative correlation was found between mycelial growth rate of Botrytis fabae and virulence
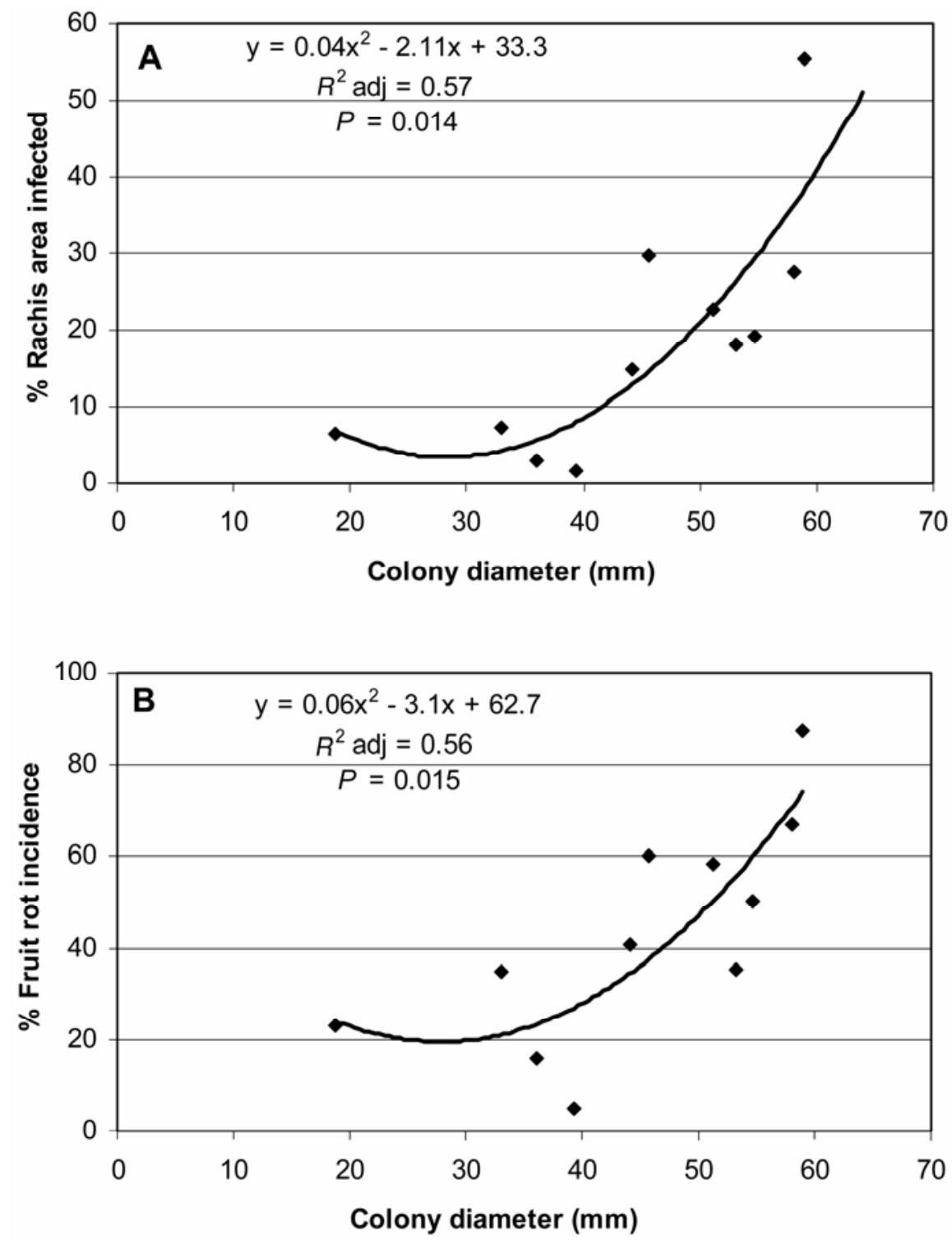

Fig. 5. Correlation between mycelial growth rate (colony diameter on potato dextrose agar after 7 days at $25^{\circ} \mathrm{C}$ in exp. 2) of Phomopsis viticola isolates from grapevine and disease severity on $\mathbf{A}$, fruit clusters, and B, rachises of grapevines (Vitis interspecific hybrid 'Seyval') inoculated in the greenhouse. Non- $P$. viticola isolates $(\mathrm{OH}-48$ and CAL-5) are not included. 
on faba bean in Egypt (1) and of Botrytis cinerea on grapevine leaves (10). While toxins and enzymes are usually implicated as virulence factors on vegetative tissues, mycelial growth rate may be a determinant of virulence on senescing plant tissues. For instance, faster-growing isolates of $P$. viticola may be better at colonizing grape berries and rachises as they are ripening and senescing. At that time, rachis lesions expand rapidly, and $P$. viticola may be seen entering the berries through the vascular tissues (A. M. C. Schilder, unpublished). By this reasoning, no correlation would be expected with the number of lesions per leaf, since that is primarily a function of the number of spores that land on and successfully infect a leaf. In fact, a slight but significant negative correlation was found between growth rate and virulence in this case, which concurs with findings on $\mathrm{Bo}$ trytis spp. $(1,10)$. There also was no relationship between mycelial growth rate and diseased internode area. This indicates that for green and actively growing tissues, factors other than mycelial growth rate affect virulence of $P$. viticola isolates.

In general, differences between $P$. viticola isolates observed in this study were quantitative in nature, and no clear biotypes could be distinguished. Future studies using more variable markers such as microsatellites or amplified fragment length polymorphisms may be required to resolve these differences.

\section{ACKNOWLEDGMENTS}

We gratefully acknowledge the assistance of Andrea Lobert and Wendy Mann in the morphological and cultural studies and Alexandra Kravchenko in the statistical analysis. We also thank the following people for providing Phomopsis isolates: Lizel Mostert and Pedro Crous for the neotype isolate of $P$. viticola, Wendy McFaddenSmith for isolates from Canada, Wayne Wilcox for isolates from New York, Brian Hed and James Travis for isolates from Pennsylvania, and Doug Gubler for isolates from California and Europe.
This project was funded in part by the USDA Viticulture Consortium East, the Michigan Grape and Wine Industry Council, and the Ohio Grape Industries Program.

\section{LITERATURE CITED}

1. Abou-Zeid, N. M., El-Morsy, G. A., Hassaneien, A. M., El-Hady, M. M., and AbdelRahman, S. S. 1998. Isolates of Botrytis spp. and the chocolate spot of faba bean in Egypt. Egypt. J. Agric. Res. 76:479-488.

2. Carbone, I., and Kohn, L. M. 1999. A method for designing primer sets for speciation studies in filamentous ascomycetes. Mycologia 91:553-556.

3. Cunningham, C. W. 1997. Can three incongruence tests predict when data should be combined? Mol. Biol. Evol. 14:733-740.

4. Eichorn, K. W., and Lorenz, D. H. 1977. Phänologische Enwicklungsstadien der Rebe. Nachrbl. Dtsch. Pflanzenschutzd. (Braunschweig) 29:119-120 .

5. Erincik, O., Madden, L. V., Ferree, D. C., and Ellis, M. A. 2000. Time of grape berry and rachis tissue susceptibility to infection by Phomopsis viticola. (Abstr.) Phytopathology 90:S21.

6. Felsenstein, J. 1985. Confidence limits on phylogenies: An approach using the bootstrap. Evolution 6:227-242.

7. Horsfall, J. G., and Barratt, R. W. 1945. An improved grading system for measuring plant disease. Phytopathology 35:655

8. Kuo, K., and Leu, L. S. 1998. Phomopsis vitimegaspora: A new pathogenic Phomopsis from vines. Mycotaxon 66:497-499.

9. Lima, E. F., and Chaves, G. M. 1992. Variability of Colletotrichum gossypii var. cephalosporioides. Fitopatol. Bras. 17:61-66.

10. Martinez, F., Blancard, D., Lecomte, P., Levis, C., Dubos, B., and Fermaud, M. 2003. Phenotypic differences between vacuma and transposa subpopulations of Botrytis cinerea. Eur. J. Plant Pathol. 109:479-488.

11. Merrin, S. J., Nair, N. G., and Tarran, J. 1995. Variation in Phomopsis recorded in grapevine in Australia and its taxonomic and biological implications. Australas. Plant Pathol. 24:44-56.

12. Mostert, L., Crous, P. W., Kang, J.-C., and Phillips, A. J. L. 2001. Species of Phomopsis and a Libertella sp. occurring on grapevines with specific reference to South Africa: Morphological, cultural, molecular and pathological characterization. Mycologia 93:146-167.

13. Niekerk, J. M., van, Groenewald, J. Z., Farr, D. F., Fourie, P. H., Halleen, F., and Crous, P. W.
Reassessment of Phomopsis species on grapevines. Australas. J. Plant Pathol. In press.

14. Pearson, R. C., and Goheen, R. C. 1994. Compendium of Grape Diseases. American Phytopathological Society, St. Paul, MN.

15. Phillips, A. J. L. 1999. The relationship between Diaporthe perjuncta and Phomopsis viticola on grapevines. Mycologia 91:10011007.

16. Pioli, R. N., Morandi, E. N., Martinez, M. C. Lucca, F., Tozzini, A., Bisaro, V., and Hopp, H. E. 2003. Morphologic, molecular, and pathogenic characterization of Diaporthe phaseolorum variability in the core soybeanproducing area of Argentina. Phytopathology 93:136-146.

17. Raper, C. A., and Raper, J. R. 1972. Genetic analysis of the life cycle of Agaricus bisporus. Mycologia 64:1088-1117.

18. Rawnsley, B., Wicks, T. J., Scott, E. S., and Stummer, B. E. 2004. Diaporthe perjuncta does not cause Phomopsis cane and leaf spot disease of grapevine in Australia. Plant Dis. 88:1005-1010.

19. Sander, G. M., and Korsten, L. 2002. Use of correlation analysis for the study of anthracnose on avocados and mangoes in South Africa. Acta Hortic. 575 (Vol. 2):681-687.

20. Scheper, R. W. A., Crane, D. C., Whisson, D. L., and Scott, E. S. 2000. The Diaporthe teleomorph of Phomopsis taxon 1 on grapevine. Mycol. Res. 104:226-231.

21. Trail, F., and Köller, W. 1990. Diversity of cutinases from plant pathogenic fungi: Evidence for a relationship between enzyme properties and tissue specificity. Physiol. Mol. Plant Pathol. 36:495-508.

22. Uecker, F. A., and Kuo, K.-C. 1992. A new Phomopsis with long paraphyses. Mycotaxon 44:425-433.

23. Vidic, M., Jasnic, S., and Jockovic. 1998. Occurrence of Phomopsis longicolla Hobbs on soybean in Yugoslavia. Acta Phytopathol. Entomol. Hung. 33:313-321.

24. Viguié, A., Vear, F., and de Labrouhe, D. T. 1999. Interactions between French isolates of Phomopsis/Diaporthe helianthi Munt.-Cvet. et al. and sunflower (Helianthus annuus L.) genotypes. Eur. J. Plant Pathol. 105:693-702.

25. White, T. J., Bruns, T., Lee, S., and Taylor, J. 1990. Amplification and direct sequencing of fungal ribosomal RNA sequences for phylogenetics. Pages 315-322 in: PCR Protocols: A Guide to Methods and Applications. Academic Press, San Diego, CA. 